\title{
Memory Enhancement with Event-Related Stimulation of the Rostral Intralaminar Thalamic Nuclei
}

\author{
Robert G. Mair and Jacqueline R. Hembrook \\ Department of Psychology, University of New Hampshire, Durham, New Hampshire 03824
}

The rostral intralaminar thalamic nuclei (ILn) are organized to activate pathways originating in medial prefrontal cortex (mPF) that mediate memory-guided responding during alert, wakeful states. Previous studies have shown that rostral ILn or mPF lesions produce deficits in delayed matching to position (DMTP). Here, we manipulated rostral ILn activity in rats by microinjecting drugs or applying electrical current and examined effects on DMTP. Inhibiting activity with the $\mathrm{GABA}_{\mathrm{A}}$ agonist muscimol impaired DMTP. Decreasing $\mathrm{GABA}_{\mathrm{A}}$ tone with FG-7142 ( $N$-methyl- $\beta$-carboline-3-carboxamide) improved DMTP at low but not high doses. Orexin A, which depolarizes thalamocortical neurons locally within the ILn, improved DMTP, whereas the cholinergic agonist carbachol impaired performance at the highest dose tested. These drug effects were unaffected by partial mPF lesions in a subset of animals. Microinjection results are consistent with an inverted-U relationship between thalamic activity and DMTP. This relationship was confirmed by event-related electrical stimulation, which produced improvement at low stimulation currents and impairment at higher currents. Electrical stimulation affected DMTP when applied at the start of the memory delay or choice response, but not earlier when trials began or the sample lever was presented. Our results are consistent with evidence that the rostral ILn play a role in retrieval, carrying response-related information across brief memory delays and facilitating memory-guided responding. They also provide evidence that treatments stimulating rostral ILn activity may be an effective means to enhance working memory and related cognitive processes and thus to treat disorders that affect these functions.

Key words: deep brain stimulation; central thalamus; working memory; $\mathrm{GABA}_{\mathrm{A}}$; orexin; acetylcholine

\section{Introduction}

The rostral intralaminar thalamic nuclei (ILn) have been proposed as a site for stimulating cognitive function based on their role in maintaining alert, wakeful states and their influence on broadly distributed neural networks involving frontal cortex and basal ganglia (Schiff and Purpura, 2002; Van der Werf et al., 2002; Schiff, 2008). Functional imaging has revealed correlations between neural activity in central thalamus and behavioral state, ranging from general anesthesia and sleep to wakefulness and activation when demands are placed on attention or working memory (Kinomura et al., 1997; Paus, 2000; Burianova and Grady, 2007). Focal lesions in these areas produce disorders of consciousness affecting arousal, attention, intention, memory, and awareness (Mair, 1994; Van der Werf et al., 2000; Schiff, 2008). Recent case reports indicate that restoration of rostral ILn function either through spontaneous recovery (Laureys et al., 2000) or deep brain stimulation (DBS) (Schiff et al., 2007) can lead to behavioral recovery in persistent vegetative or minimally conscious patients. Rostral ILn stimulation in the rat is reported

\footnotetext{
Received July 15, 2008; revised Nov. 18, 2008; accepted Nov. 19, 2008.

This work was supported by National Institute of Neurological Disorders and Stroke Grant NS26855. We thank Lori Newman, Zach Beer, Lyndsay Schneiderman, James Wrocklage, and Owen Glotzer for assistance conducting these studies.

Correspondence should be addressed to Robert G. Mair, Department of Psychology, University of New Hampshire, Durham, NH 03824. E-mail: rgm@unh.edu.

DOI:10.1523/JNEUROSCI.3301-08.2008

Copyright $\odot 2008$ Society for Neuroscience $\quad 0270-6474 / 08 / 2814293-08 \$ 15.00 / 0$
}

to induce immediate-early gene expression in cerebral cortex and increase time spent exploring novel objects (Shirvalkar et al., 2006).

Lesion studies have revealed impairments of delayed matching to position (DMTP) and other measures of working memory in rats with rostral ILn or medial prefrontal cortex ( $\mathrm{mPF}$ ) lesions (Mair et al., 1998; Bailey and Mair, 2004, 2005). Here, we manipulated rostral ILn activity by microinjecting drugs or applying electrical stimulation and examined effects on DMTP. We microinjected muscimol and $N$-methyl- $\beta$-carboline-3-carboxamide (FG-7142) to inhibit and excite neurons through $\mathrm{GABA}_{\mathrm{A}}$ receptors distributed ubiquitously throughout thalamus (McCormick et al., 1997), orexin A to depolarize neurons locally within the ILn (Bayer et al., 2002), and carbachol to mimic the depolarizing effects of acetylcholine released from processes originating in mesopontine cholinergic nuclei (Curró Dossi et al., 1991). We expected to find inverted U-shaped dose-response curves: performance improving with stimulation up to an optimal level and deteriorating at higher levels of activation (Arnsten, 2007). To test the clinical usefulness of drug treatments, we included rats with and without lesions partially damaging $\mathrm{mPF}$ areas innervated by the rostral ILn and known to affect DMTP (Berendse and Groenewegen, 1991; Mair et al., 1998; Shirvalkar et al., 2006).

Neurons in the ILn and adjacent paralaminar regions of central thalamus exhibit precisely timed responses to behaviorally significant events on a much shorter timescale than the effects produced by microinjected drugs (Matsumoto et al., 2001; Mi- 
namimoto and Kimura, 2002; Wyder et al., 2004; Tanibuchi and Goldman-Rakic, 2005; Tanaka, 2007). Central thalamic activity is increased in functional imaging studies during later phases of working memory trials, suggesting a role in retrieval or memoryguided responding in human subjects (Manoach et al., 2003; Burianova and Grady, 2007). To examine the consequences of such brief changes in activity, we compared effects of similarly brief trains of electrical pulses delivered at different stages of DMTP trials. We manipulated the level of stimulating current in this study to confirm the inverted-U-shaped relationship between neural activity and DMTP suggested by results of the microinjection studies.

\section{Materials and Methods}

Animals. Subjects were 60 male Long-Evans rats, 8 weeks of age at the start of the study, obtained from Harlan. Each of the two microinjection studies used 20 rats ( 10 with $\mathrm{mPF}$ lesions and 10 sham lesioned controls). The $\mathrm{mPF}$ lesions were included to examine the effects of drug treatments in rats with partial disruption of neural networks linked to the rostral ILn and implicated in DMTP performance. Another 20 were implanted with electrodes aimed bilaterally at the rostral ILn for electrical stimulation studies. All rats were trained to perform the DMTP task to a criterion of completing 40 trials with $85 \%$ correct within a 60 min session before surgery. Rats were given ad libitum food and caged singly on a $12 \mathrm{~h}$ light/dark cycle with training during the light phase. Access to water was restricted to training sessions and to $30 \mathrm{~min}$ of ad libitum access at the end of the light cycle so that water could be used as a reinforcer. The period of ad libitum access was increased to a minimum of $60 \mathrm{~min}$ on days when rats were not trained.

Apparatus. DMTP was trained in operant chambers equipped with three retractable levers (two on the front wall and one on the back), a water dipper (placed between the two front levers), and a house light (obtained from MED Associates). For microstimulation experiments, one of these chambers was equipped with a four-channel commutator (SL2X2C; Plastics One) that allowed each of two bipolar electrodes to be connected with the output of a stimulus isolator (A 365; WPI) for constant current stimulation. Event-related stimulation was delivered by driving two stimulus isolators with a train of TTL pulses from a Pulsar stimulator (FHC) that was triggered by the interface (MED Associates) used to control the DMTP task. DMTP chambers were inside soundinsulating enclosures to minimize external distractions. The soundinsulating chamber used for electrical stimulation was equipped with a window that allowed direct observation of rats during stimulation sessions to insure that the currents applied did not disrupt motor aspects of responding.

Surgery. Rats were anesthetized by intramuscular injection of ketamine $(85 \mathrm{mg} / \mathrm{kg})$ and xylazine $(8.5 \mathrm{mg} / \mathrm{kg})$, and surgeries were performed using aseptic procedures. Electrodes and cannulas (guide cannulas, internal cannulas, dummy cannulas, and dust caps) and supplies for implanting them [cranioplastic cement and stainless-steel (SS) machine screws] were obtained from Plastics One. For microinjection studies rats were placed in a Kopf stereotaxic instrument with the incisor bar set 3.3 $\mathrm{mm}$ below the interaural line (IA). For electrical stimulation, rats were positioned in the same orientation in a Stellar-type (ANY-angle) stereotaxic instrument (Stoelting) to implant electrodes at an angle. A longitudinal incision was made along the midline, the skin was retracted to expose the surgical field, and the periosteum was scraped away. Holes were then drilled and four SS machine screws implanted at the anterior and posterior lateral extremes of the surgical field. The skull was then opened with a trephine.

For microinjection studies, dual guide cannulas were implanted with tips ending at $6.2 \mathrm{~mm}$ anterior and $6.0 \mathrm{~mm}$ dorsal with regard to the IA and centered $1 \mathrm{~mm}$ on either side of midline. One-half of the rats in the microinjection studies also received $\mathrm{mPF}$ lesions by injecting $0.1 \mu \mathrm{l}$ of $100 \mathrm{~mm}$ NMDA through 26 gauge cannulas $(0.2 \mu \mathrm{l} / \mathrm{min}$ using a Kopf 5000 microinjection unit $)$ at six sites in each hemisphere $( \pm 0.8 \mathrm{~mm}$ from midline): $2.0 \mathrm{~mm}$ anterior from bregma, 3.0 and $4.0 \mathrm{~mm}$ below the surface of cortex; $3.0 \mathrm{~mm}$ anterior from bregma, 2.5 and $3.5 \mathrm{~mm}$ below the surface; and $4.0 \mathrm{~mm}$ anterior from bregma, 2.0 and 3.0 below the surface. Guide cannulas were then attached to the SS machine screws with cranioplastic cement, dummy cannulas were inserted (cut flush with the end of the guide cannulas to insure that they remained patent), and a dustcap was attached. The incision was sutured and butorphanol $(0.2 \mathrm{mg} / \mathrm{kg}$, s.c. $)$ administered as postsurgical analgesia.

For electrical stimulation studies, electrodes (twisted pairs of 0.125 $\mathrm{mm}$ SS with polyimide insulation; MS303-3; Plastics One) were implanted at an angle of $15-20^{\circ}$ away from the midline on either side of thalamus to allow room for cables to be attached to both electrodes at the same time. Electrodes were aimed at sites $6.2 \mathrm{~mm}$ anterior and $4.6 \mathrm{~mm}$ dorsal to IA and $1.4 \mathrm{~mm}$ off midline on each side of thalamus. To do this, one electrode was positioned and held in place by a small amount of cranioplastic cement attaching it to two of the four SS machine screws on the same side of the skull, while the second electrode was implanted. Both electrodes were then attached to all four screws with a larger amount of cement. The incision was sutured, and butorphanol ( $0.2 \mathrm{mg} / \mathrm{kg}$, s.c.) was administered as postsurgical analgesia.

Behavioral training. DMTP was trained using procedures described in previous studies (Porter et al., 2001; Bailey and Mair, 2005). Each DMTP trial consisted of a series of four lever press responses. Trials began with back lever extended. This retracted when pressed (initiation) causing one of the two front levers (randomly selected) to extend as the sample for the trial. This retracted when pressed (sample response) causing the back lever to extend and the retention interval (RI) to start. This retracted with the first lever press after the RI ended (delay response), causing both front levers to extend for the choice response. When the lever first pressed for the choice was the same as the sample (a correct DMTP response), the dipper was raised to deliver reinforcement ( $0.1 \mathrm{ml}$ of tap water). During microinjection studies, RIs were changed randomly from trial to trial within session $(1,3,8$, or $13 \mathrm{~s}$ in the first study and $1,6,12,20$, or $30 \mathrm{~s}$ in the second) to vary demands on working memory. During electrical stimulation studies, RI was held constant across trials within session (at 1 , 13 , or $23 \mathrm{~s}$ in different experiments) so that sufficient data could be recorded to compare effects of stimulation at different times during DMTP trials (none, initiate, sample, delay, or choice). DMTP sessions lasted for a maximum of 75 trials or $60 \mathrm{~min}$. Rats were trained to a criterion of completing at least 40 trials with $85 \%$ correct within a $60 \mathrm{~min}$ session before surgery.

Microinjection procedures. After 2 weeks of recovery from surgery, rats were trained back to a criterion of completing 40 trials within a $60 \mathrm{~min}$ session. To avoid carryover effects, rats were required to reach this criterion (without an injection) before each injection session. This meant that all animals had at least $1 \mathrm{~d}$ of baseline training (without an injection) between treatment sessions. Rats were handheld; dust caps and dummy cannulas were removed; and an internal cannula was inserted that extended $2 \mathrm{~mm}$ beyond the tips of the guide cannulas. Anatomical controls were tested where justified by the size of treatment effects by injecting drugs $1.5 \mathrm{~mm}$ dorsal to the ILn site $(0.5 \mathrm{~mm}$ below the guide cannulas). Drugs were diluted to a volume of $0.5 \mu \mathrm{l}$ and injected at a rate of 1.0 $\mu \mathrm{l} / \mathrm{min}$. Cannulas were then left in place for $1 \mathrm{~min}$ after injections were completed. Dummy cannulas and dust caps were then replaced and rats were returned to their home cage for $10 \mathrm{~min}$ before being placed in operant chambers for behavioral testing. No animals received more than two injections in a given week.

Each drug was tested in a series of sessions. Each animal received each dose once with the order of doses counterbalanced between animals by block randomization. In the first microinjection study, rats were treated with orexin $\mathrm{A}(0,0.01,0.1 \mathrm{nmol})$, and then carbachol $(0,0.01,0.1,1.0$ $\mathrm{nmol})$, and last FG-7142 $(0,0.01,0.1,1.0,10.0 \mathrm{nmol})$. In the second study, rats were treated first with FG-7142 $(0,0.01,0.1,1.0,10.0 \mathrm{nmol})$ and then muscimol $(0,0.1,0.3$, and $1.0 \mathrm{nmol})$. Carbachol, muscimol, and FG-7142 were obtained from Sigma-Aldrich and orexin A from Peninsula Laboratories.

Event-related electrical stimulation. Preliminary studies in which stimulation was applied for $10 \mathrm{~s}$ during the choice phase of DMTP indicated that $0.1 \mathrm{~ms}$ pulses at $120 \mathrm{~Hz}$ were effective parameters to enhance DMTP with low levels $(0.01 \mathrm{~mA})$ of stimulating current (supplemental Fig. 1, available at www.jneurosci.org as supplemental material). Initially, a 

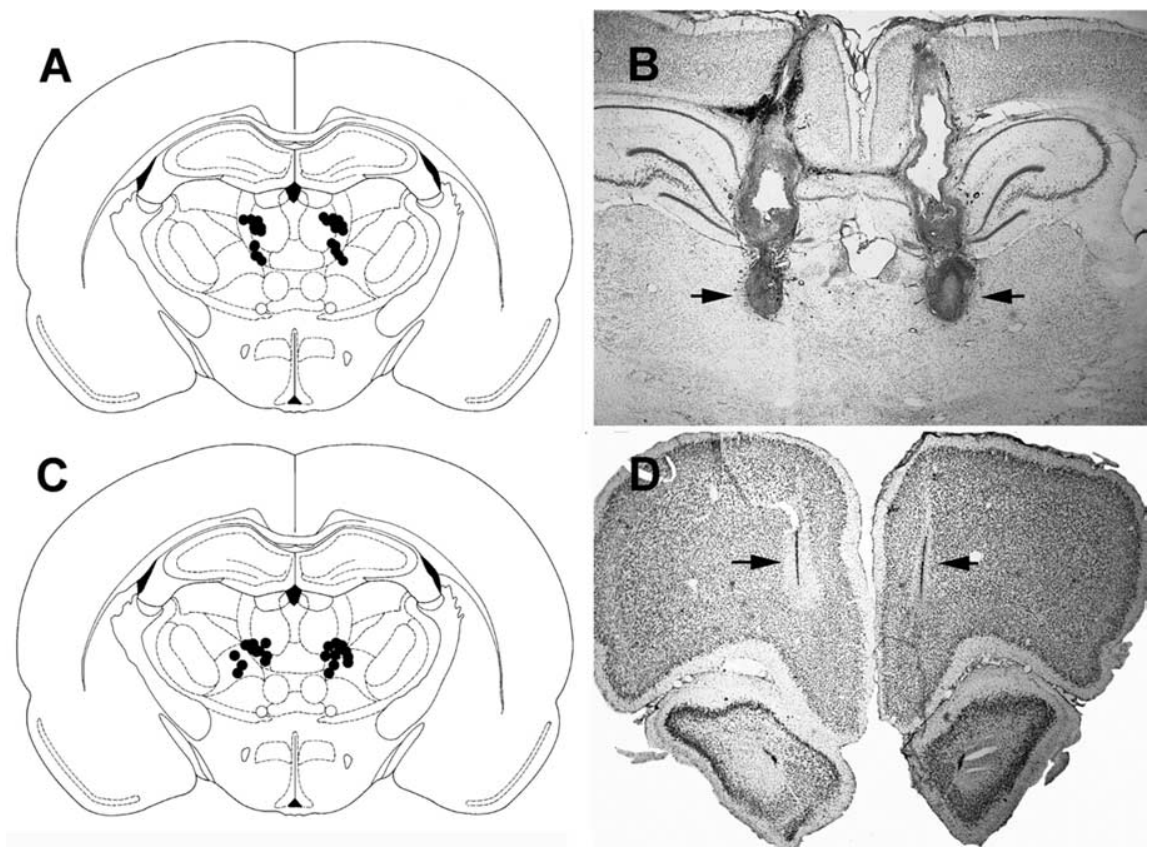

Figure 1. Histological results from the microinjection studies. $\boldsymbol{A}, \boldsymbol{C}$, Locations of injection sites in the first $(\boldsymbol{A})$ and second $(\boldsymbol{C})$ microstimulation studies. Sites are depicted on a coronal section $6.2 \mathrm{~mm}$ from the interaural line (Paxinos and Watson, 1998). $\boldsymbol{B}$, Photomicrographs of representative injection sites (indicated by arrows). Note the greater extent of damage produced by guide cannulas that ended $2 \mathrm{~mm}$ dorsal to the injection site. D, Photomicrograph of representative mPF lesions (indicated by arrows).
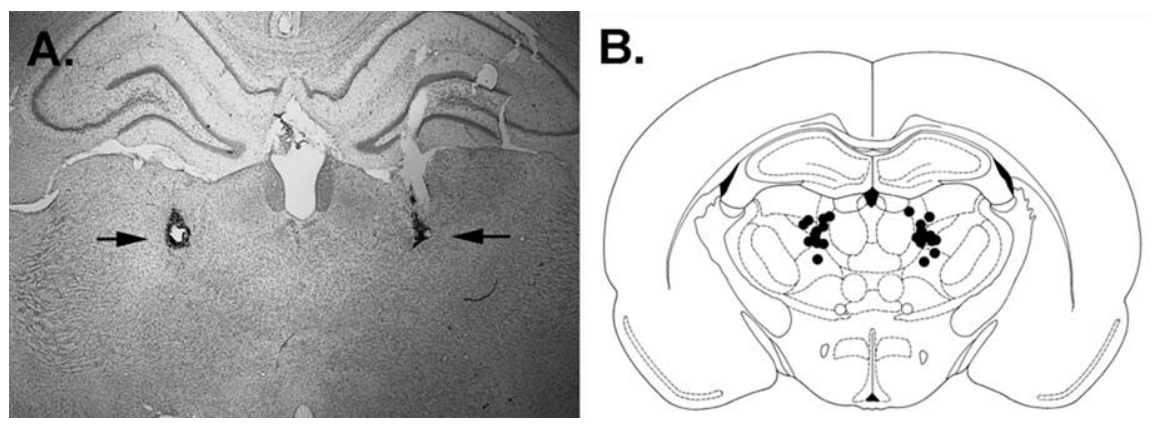

Figure 2. Histological results for event-related electrical stimulation studies. $\boldsymbol{A}$, Photomicrograph of representative stimulation sites (indicated by arrows). $\boldsymbol{B}$, Locations of electrical stimulation sites depicted on a coronal section $6.2 \mathrm{~mm}$ from the interaural line (Paxinos and Watson, 1998).

staircase procedure was used to determine the threshold current (with a $1 \mathrm{~s}$ train of $0.2 \mathrm{~ms}$ pulses at $120 \mathrm{~Hz}$ ) for individual rats that caused them to pause while performing a continuous lever-pressing task. During subsequent DMTP stimulation experiments, current levels were adjusted between sessions at levels at least 33\% below this threshold. Each DMTP stimulation session consisted of a random sequence of five types of stimulation trials: stimulation when levers were inserted for initiation, sample, delay (RI), or choice responses and trials in which no stimulation was delivered. In an initial series of sessions, a number of current levels were tested on an individual basis covering a range of at least $0.01-0.1 \mathrm{~mA}$. These results were used to determine a high level sufficient to impair DMTP performance and a low level selected to enhance performance. Current level (high, low, or none) was then varied between sessions counterbalanced by block randomization until rats completed a minimum of three sessions and 120 trials for each of the current levels.

Histological processing. On completion of behavioral testing, rats were given a terminal dose of anesthesia (100 mg/kg ketamine; $10 \mathrm{mg} / \mathrm{kg}$ xylazine) and perfused with $0.9 \%$ saline followed by $4 \%$ formalin in phosphate-buffered solution transcardially. Brains were removed and placed in a solution of 5\% formalin, 2\% DMSO, and 20\% glycerin until they were ready to be sectioned. Tissue was sectioned frozen at $50 \mu \mathrm{m}$,

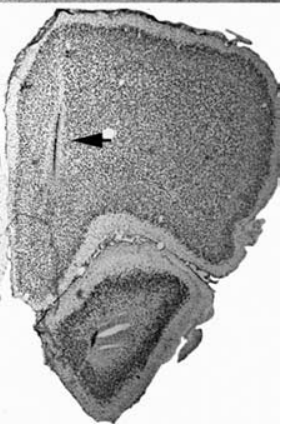

and sections were mounted and stained with cresyl violet. Sections were examined to confirm that injection and stimulation sites were proximate to the rostral ILn and to determine the extent of damage produced by the $\mathrm{mPF}$ lesions.

Statistical analyses. DMTP performance was measured as percentage correct and analyzed by ANOVAs. For microinjection studies, dose and RI were analyzed as within-subject factors and lesion group as a between-subjects factor. To combine results between studies for FG-7142, data were collapsed across RI (which differed between studies), and experiment (first vs second microinjection study) was entered as a between-subjects factor to confirm that comparable drug effects were observed in each study. For electrical stimulation studies, current level and stimulation trial type (when or if stimulation was delivered) were analyzed as withinsubject factors and RI as a between-subjects factor (different animals were tested at different RIs). Post hoc testing (Games-Howell, $\alpha=0.05$ ) was used to compare effects of different drug doses or stimulation currents when main effects were significant. The Bonferroni procedure was used to adjust $\alpha$ values when effects of stimulating currents were evaluated for different stimulating trial types. One-way ANOVAs were used to evaluate simple main effects for significant two-way interaction effects, with Bonferroni's corrections for multiple comparisons.

\section{Results \\ Histology}

For microinjection studies, dual-guide cannulas were $2.0 \mathrm{~mm}$ apart (aimed 1.0 $\mathrm{mm}$ on either side of midline) and extended $5.5 \mathrm{~mm}$ from the base of the pedestal. Microinjections were made from internal cannulas that extended $2 \mathrm{~mm}$ below this. Histological analyses revealed relatively wide tracks from guide cannulas that ended just above thalamus and damage associated with injection sites below this (Fig. 1B). Microinjection sites were localized as centered $2 \mathrm{~mm}$ below the end of guide cannulas (which could be determined unequivocally in all cases) within the area of damage around the injection site (Fig. $1 A, C$ ). One-half of the animals in each of the microinjection studies had mPF lesions. These primarily involved prelimbic cortex and had the characteristic appearance of excitotoxic lesions: tissue loss and areas of gliosis marked by a lack of neurons and proliferation of glial cells (Fig. $1 D$ ). The tips of electrodes used for electrical stimulation tended to be slightly more lateral and produced less tissue damage than the cannulas used for microinjection studies (Fig. 2). All microinjection and electrical stimulation sites were within $1.0 \mathrm{~mm}$ of the intended rostral ILn site, and thus no rats were excluded from analyses based on histological findings.

\section{Behavioral results}

Microinjection studies

For both treatment groups, decreasing $\mathrm{GABA}_{\mathrm{A}}$ inhibition with FG-7142 produced the predicted inverted-U-shaped dose-response curve, with the highest percentage correct at the $0.1 \mathrm{nmol}$ 
dose and the lowest at the $10 \mathrm{nmol}$ dose (Fig. $3 A$ ). In contrast, stimulating $\mathrm{GABA}_{\mathrm{A}}$ receptors with muscimol produced dosedependent DMTP impairment (Fig. 3C). Thus, decreasing GABAergic tone with FG-7142 enhanced performance over a limited range of doses, whereas increasing GABAergic tone with muscimol produced increased impairment at higher doses. Neither of these drug effects interacted significantly with the length of the RI (Fig. $3 B, D)$ or the effects of the mPF lesion. The effects of the highest muscimol dose (1 $\mathrm{nmol})$ were eliminated when injected 1.5 $\mathrm{mm}$ dorsal to the rostral ILn as an anatomical control (Fig. 3C).

An omnibus ANOVA revealed a significant effect of FG-7142 dose $\left(F_{(4,116)}=\right.$ $3.488 ; p=0.010)$ and confirmed that these effects did not interact between studies $(F<1)$ or lesion groups $\left(F_{(4,116)}=1.226\right.$; $p=0.3038)$. There were significant effects of RI in both studies (values of $p<0.0001$ ) that did not interact with drug effects (values of $F<1$ ). Muscimol produced dosedependent impairment in response accu$\operatorname{racy}\left(F_{(3,36)}=5.58 ; p=0.003\right)$ that did not interact with the effects of the $\mathrm{mPF}$ lesion $(F<1)$. The significant effect of $1.0 \mathrm{nmol}$ of muscimol was eliminated (GamesHowell, $\alpha=0.05$ ) when injected $1.5 \mathrm{~mm}$ dorsal to central thalamus as an anatomical control. There was a significant effect of RI $(p<0.0001)$ that did not interact with muscimol dose $(F<1)$.

Orexin A was associated with delay-dependent improvement that was significant at the longest delay (RI, $13 \mathrm{~s}$ ) tested (Fig. $4 A, B)$. The overall effect of orexin A was not statistically significant $\left(F_{(2,32)}=1.446 ; p=0.25\right)$; however, there was a significant interaction between dose and $\mathrm{RI}\left(F_{(6,96)}=3.229 ; p=0.0062\right)$. Analyses of simple main effects revealed a significant effect of orexin at RI of $13 \mathrm{~s}(p<0.05)$, but not at shorter delays. The effects of orexin A did not interact with the effects of the prefrontal lesion $(F<1)$. Carbachol impaired performance significantly at the highest dose tested (Fig. $4 C, D)$. Carbachol produced dosedependent impairment $\left(F_{(3,48)}=3.610 ; p=0.020\right)$ significant at the highest dose tested (Games-Howell, $\alpha=0.05$ ). The effects of carbachol did not interact with the effects of the mPF lesion or the length of the RI (values of $F<1$ ).

\section{Effects of mPF lesions}

The effects of the mPF lesions did not interact with any of the drug effects (values of $p>0.30$ ). Previous studies have shown that prefrontal lesions involving cingulate and prelimbic areas of prefrontal cortex have significant effects on DMTP (Mair et al., 1998). Our mPF lesions involved more limited areas of cingulate cortex than in this previous study, and our experiments were not designed to test the effects of mPF lesions on DMTP performance. Nevertheless examining group differences during drug treatments in the two microinjection studies can assess lesion effects. In the first study, there was a significant effect of mPF lesions during the first set of drug trials (orexin $\mathrm{A} ; F_{(1,16)}=6.300$; $p=0.0232$ ). This trend was still apparent during the second set of drug trials (carbachol), although it was no longer statistically SEM in this and subsequent figures.
B.

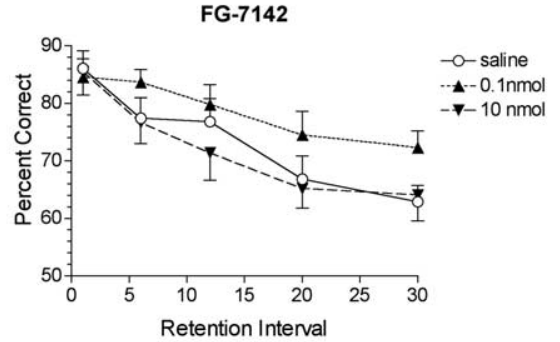

D.

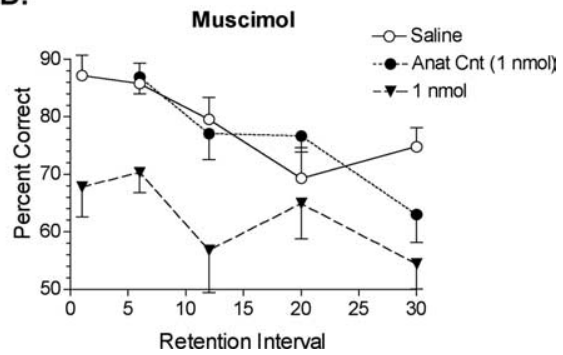

Figure 3. Manipulations of inhibitory $\mathrm{GABA}_{A}$ activity. $A$, Averaged across studies, FG-7142 affected both sham and prefrontal shown here for saline compared with $1 \mathrm{nmol}$ of muscimol in central thalamic and anatomical control sites. Error bars represent

significant $\left(F_{(1,13)}=3.772 ; p=0.0741\right)$. It was no longer apparent during the FG-7142 trials $(F<1)$. Although the lesions were similar in the second microinjection group, they did not have an apparent effect during either the FG-7142 or muscimol trials (values of $F<1$ ).

\section{Event-related electrical stimulation}

DMTP trials consist of a series of four lever presses that correspond to distinct processes of working memory (Fig. 5A). These include the following: initiation (preparation), sample (stimulus encoding), delay (maintenance of information in memory), and choice (retrieval, memory-guided responding). After recovery from surgery, rats were trained back to criterion and individual thresholds established for the minimal current that caused rats to pause while performing a lever-pressing task (Fig. 5B, "pause" currents). Stimulation currents were kept at least 33\% below this level in subsequent experiments. DMTP was tested in five stimulation conditions: no stimulation versus application of $1 \mathrm{~s}$ trains of current pulses $(0.2 \mathrm{~ms}$ at $120 \mathrm{~Hz})$ at the start of the initiation, sample, delay, or choice phases. Stimulating conditions were varied randomly between trials within sessions. Stimulation current was varied between sessions. Each animal was first tested for a series sessions with currents covering a range of at least $0.01-0.1$ $\mathrm{mA}$ (supplemental Fig. 2, available at www.jneurosci.org as supplemental material). These results were used to determine a high level sufficient to impair DMTP performance and a low level selected to enhance performance (Fig. 5B). DMTP was then trained with current level (high, low, or none) varied between sessions counterbalanced by block randomization until rats completed a minimum of three sessions and 120 trials for each of the current levels. 
A.

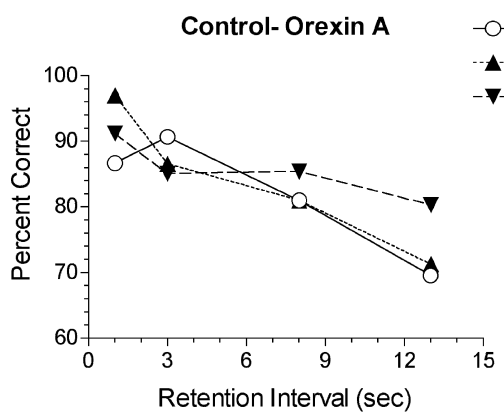

c.

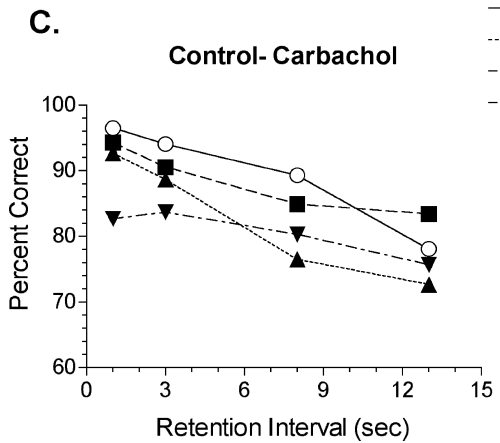

B.

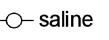

A- $0.01 \mathrm{nmol}$

$-0.1 \mathrm{nmol}$

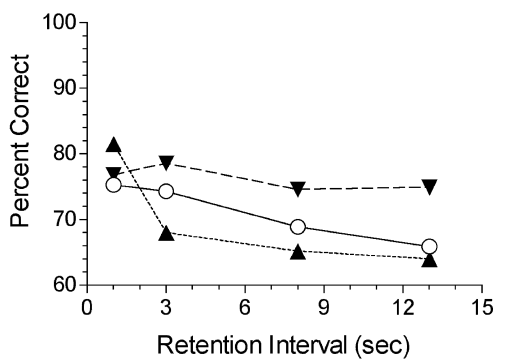

D.

$-0.01 \mathrm{nmol}$

$-0.1 \mathrm{nmol}$

$-1.0 \mathrm{nmol}$

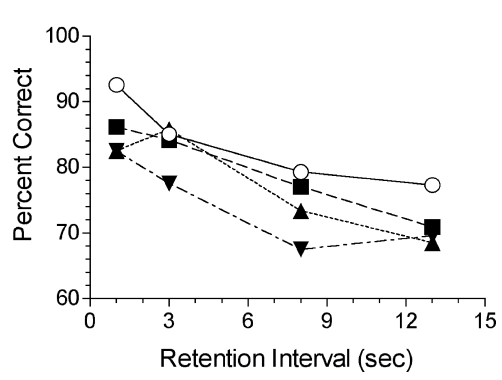

Figure 4. Effects of orexin $A$ and carbachol. $\boldsymbol{A}, \boldsymbol{B}$, The $0.1 \mathrm{nmol}$ dose of orexin A tended to improve performance at longer delays for both control $(\boldsymbol{A})$ and $\mathrm{mPF}$ lesioned $(\boldsymbol{B})$ rats. The overall effect of orexin A was not statistically significant; however, there was a significant interaction between dose and RI. Analyses of simple main effects revealed a significant effect of orexin at RI of $13 \mathrm{~s}$. The effects of orexin A did not interact with the effects of the prefrontal lesion $(F<1)$. C, $\boldsymbol{D}$, Carbachol produced dose-dependent impairment significant at the highest dose tested. The effects of carbachol did not interact with the effects of the mPF lesion or the length of the RI (values of $F<1$ ).

Complete results were obtained for eight rats for DMTP with a $1 \mathrm{~s}$ RI (Fig. 5C). These revealed a significant effect of stimulation current $\left(F_{(2,14)}=19.262 ; p<0.0001\right)$ that interacted with the time when stimulation was delivered $\left(F_{(6,42)}=7.998 ; p<\right.$ 0.0001). Analyses of simple main effects indicated significant effects of stimulation delivered at the start of the choice or delay phases (values of $p<0.0001$ ) but not at the start of the sample or initiation phases (values of $F<1$ ). The significant effect of choice stimulation is consistent with a role for central thalamus in decisional processes in memory-guided responding. It was unclear whether the effects of delay period stimulation reflected its close temporal proximity to the choice response at this short RI or if it specifically affected processes during the delay period. To test these possibilities, we increased the length of the RI $(N=5$ for each RI). These studies showed significant overall effects of stimulation when the RI was increased to $13 \mathrm{~s}\left(F_{(2,8)}=4.743 ; p=\right.$ $0.044)$ or $23 \mathrm{~s}\left(F_{(2,8)}=164.98 ; p<0.0001\right)$. Again, there were significant effects of stimulation delivered at the start of delay and choice phases, but not at earlier initiation or sample phases (Fig. $5 C)$.

An omnibus ANOVA of results at all RIs revealed significant effects of current level $\left(F_{(2,30)}=35.79 ; p<0.0001\right)$, trial type (when stimulation was delivered) $\left(F_{(3,45)}=3.568 ; p=0.021\right)$, and the interaction of these factors $\left(F_{(6,90)}=6.394 ; p<0.0001\right)$. There was no significant effect $\left(F_{(2,15)}=2.105 ; p=0.156\right)$ or interaction (values of $p>0.198$ ) with the length of the RI. Post hoc testing (Games-Howell, $\alpha=0.05$ ) showed that low currents improved and high currents impaired performance, compared with sessions without stimulation. Analyses of simple main effects revealed significant effects of delay and choice (values of $p<$
0.0001 ), but not initiation ( $p=0.072$ ) or sample ( $p=0.178)$ stimulation.

\section{Discussion}

Our results provide evidence that working memory is influenced by rostral ILn activity. Muscimol, a $\mathrm{GABA}_{\mathrm{A}}$ agonist with inhibitory effects on thalamic activity, produced dose-dependent impairment that was significant at the highest dose tested $(1.0 \mathrm{nmol})$. Decreasing inhibitory GABAergic tone with the negative allosteric modulator FG-7142 tended to enhance accuracy at low $(0.1 \mathrm{nmol})$, but not high $(10 \mathrm{nmol})$ doses. Stimulating activity with orexin A enhanced DMTP at the highest dose tested, whereas the general cholinergic agonist carbachol produced significant impairment at the highest dose. Electrical stimulation confirmed this evidence of an inverted-U-shaped relationship between thalamic activity and DMTP performance and additionally provided evidence of temporal specificity. DMTP was affected by current pulses applied during the memory delay or the choice response but not earlier at the start of the trial or the presentation of the sample.

\section{Stimulation intensity}

Manipulation of GABAergic activity with muscimol and FG-7142 provided evidence of both ascending and descending limbs of an inverted-U-shaped relationship between thalamic activity and DMTP performance. The highest dose of orexin A enhanced performance at the longest retention interval tested. Orexin selectively depolarizes and excites neurons in the ILn (Bayer et al., 2002). Thus, the effects of orexin A provide evidence of a direct influence of rostral ILn activity on DMTP. It remains to be determined whether higher doses impair performance. It is also unclear whether effects at longer RIs reflect a delay-dependent process or whether these benefits were obscured by a ceiling effect at shorter delays. Carbachol produced dose-dependent impairment consistent with the descending limb of an inverted- $U$ curve. It remains to be determined whether lower doses enhance performance. It is also uncertain whether the effects of carbachol reflect its agonist effects on both muscarinic and nicotinic receptors. Acetylcholine excites thalamic neurons through rapid nicotinic and slower muscarinic depolarizing currents (Curró Dossi et al., 1991). Microinjection studies have provided evidence of a localized effect of the nicotinic antagonist mecamylamine, but not the muscarinic antagonist scopolamine, in the rostral ILn (Newman and Mair, 2007).

Electrical stimulation provided more definitive evidence for an inverted-U relationship. Across all stimulation trials, low-level currents improved performance significantly to $80.7 \%$ correct compared with $75.9 \%$ correct for nonstimulation sessions, whereas high current stimulation reduced DMTP accuracy significantly to $63.7 \%$ correct. The impairment at higher current levels is predictable given evidence that DBS produces deficits comparable with lesions damaging the area stimulated (Perlmutter and Mink, 2006; Kringelbach et al., 2007; Schiff and Fins, 2007). The beneficial effects of low current stimulation are note- 
A. DMTP Phases

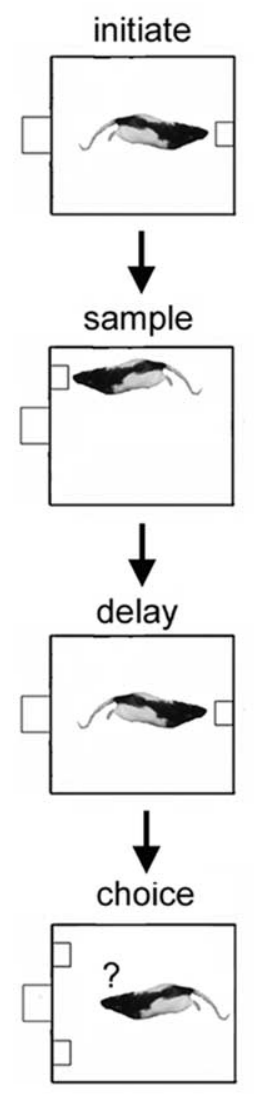

B. Current Levels

$\mathrm{RI}=1 \mathrm{~s}$

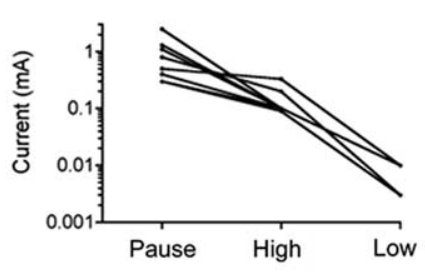

$R I=13 \mathrm{~s}$

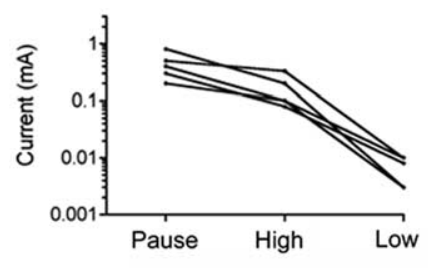

$R I=23 \mathrm{~s}$

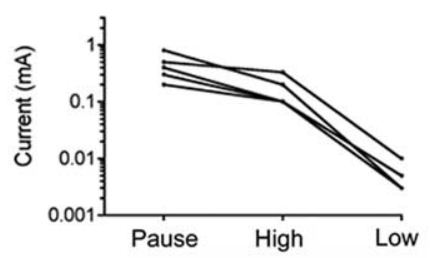

C. DMTP Accuracy

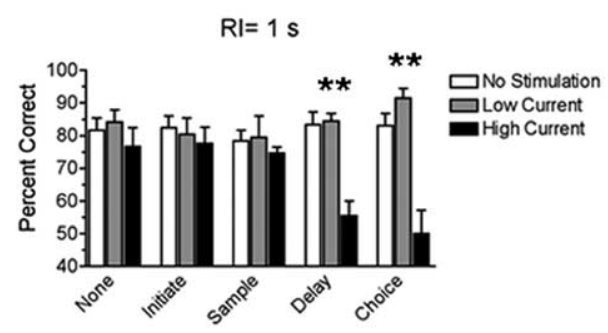

$\mathrm{RI}=13 \mathrm{~s}$

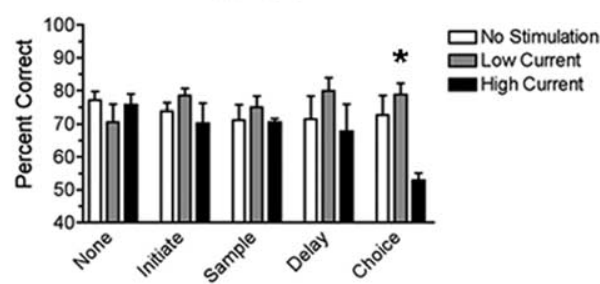

$\mathrm{RI}=23 \mathrm{~s}$

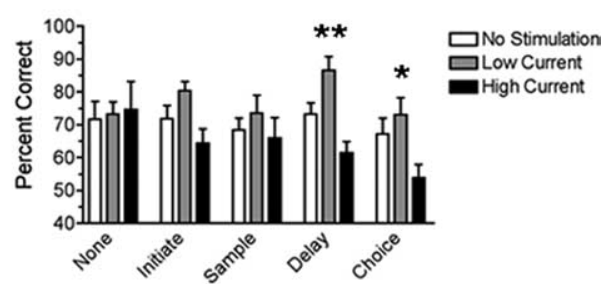

Figure 5. Event-related electrical stimulation. $\boldsymbol{A}$, Stimulation was delivered bilaterally $(0.2 \mathrm{~ms}$ pulses at $120 \mathrm{~Hz})$ for $1 \mathrm{~s}$ at the start of the initiate, sample, delay, or choice phases of DMTP. $\boldsymbol{B}$, Current levels for individual animals (connected points) showing the threshold causing rats to pause while performing a continuous lever-pressing task and the levels used for high and low current stimulation. C, Effects of stimulation at each of the three Rls tested. There were significant effects of current level, trial type (when stimulation was delivered), and the interaction of these factors. There was no significant effect or interaction with the length of the Rl. Analyses of simple main effects revealed significant effects of delay and choice, but not initiation or sample stimulation. ${ }^{*} p<$ 0.05 and $^{* *} p<0.01$, with Bonferroni's correction for multiple comparisons.

worthy, particularly given supporting evidence of similar improvement with FG-7142 and orexin A (Figs. 3, 4). Manipulation of catecholamine activity in prefrontal cortex has also provided evidence of an optimal level of activation for working memory (thus an inverted-U relationship) in areas reciprocally connected to the rostral ILn (Arnsten, 2007). The present results raise the possibility that the rostral ILn may provide an effective target for modulating activity within prefrontal cortex and related areas of striatum.

The impairments observed here at currents as low as $0.1 \mathrm{~mA}$ are surprising given a previous report of enhanced novel object recognition with $1.5 \mathrm{~mA}$ stimulation delivered at $100 \mathrm{~Hz}$ in a nearly identical site. There are important differences between the studies that may explain these inconsistencies. Here, we examined effects of stimulation on DMTP, a measure of working memory that we found to be impaired by rostral ILn lesions. We applied shorter trains of stimulation ( $1 \mathrm{~s}$ vs $30 \mathrm{~min}$ ) to vary the time when the rostral ILn were activated within DMTP trials. Finally, we applied stimulation bilaterally to be consistent with the microinjection studies. We observed little carryover in stimulation effects from trial to trial [and thus no difference for trials in which no stimulation was applied between high, low, or no stimulation sessions (Fig. 5C, "none" trials)]. In contrast, Shirvalkar et al. (2006) describe effects that increased across $3 \mathrm{~d}$ of stimulation. These data suggest that prolonged, higher-current stimulation in the previous study induced more permanent, cumulative changes in brain function than the relatively brief, lower-current stimulation applied here.

There is uncertainty inherent in localizing the site of action of microinjected drugs or electrical stimulation. Although our results are consistent with an inverted-U dose-response curve, they might also reflect a greater spread of activation for higher drug doses or stimulation currents. This is particularly true in an area like central thalamus that contains other systems that have been implicated in learning and memory. Several observations suggest that the rostral ILn are a likely site of action in the present studies. First, anatomical controls support a central thalamic site of action for muscimol. Second, orexin-containing processes innervate and depolarize neurons in midline and intralaminar nuclei while bypassing adjacent relay nuclei (Peyron et al., 1998; Bayer et al., 2002). Thus, the effects of orexin A seem likely to be localized there. Third, lesion studies have shown that DMTP is specifically affected by treatments that disrupt the rostral ILn or anatomically related areas in prefrontal cortex, striatum, or pallidum (Burk and Mair, 1998, 2001; Porter et al., 2001; Bailey and Mair, 2004, 2005; Zhang et al. 2005). Thus, convergent evidence supports a role for the rostral ILn, although it remains logically possible that the mediodorsal or midline thalamic nuclei mediated some of the effects of microinjected drugs or electrical stimulation on DMTP. 


\section{Temporal specificity of electrical stimulation}

Correlational analyses of single-neuron activity in monkeys (Watanabe and Funahashi, 2004; Wyder et al., 2004; Tanaka, 2007) and functional magnetic resonance imaging in humans (Manoach et al., 2003; Burianova and Grady, 2007) indicate that central thalamic activity is timed to coincide with delay- and retrievalrelated events in working memory tasks. Our results provide causal evidence of this relationship. Stimulation at the start of the memory delay or choice response significantly affected performance, whereas stimulation at the start of the trial or presentation of the sample lever did not. The effects of delay period stimulation persisted when the length of this period was increased from 1 to $23 \mathrm{~s}$ and thus could not easily be explained by temporal proximity to the choice response. These results are consistent with evidence that central thalamic neurons carry responserelated information across brief memory delays and mediate memory-guided responding (Wyder et al., 2004). The failure of initiation or sample stimulation to affect performance is inconsistent with a role of central thalamus in processes related to preparation for the trial or encoding information related to the sample.

\section{Clinical implications}

DBS has been shown to have substantial clinical benefits for neuropsychiatric disorders, although the precise mechanism of action remains to be established. Recordings of neurons near stimulating sites suggest that high-frequency stimulation used for DBS activates axons leaving areas of stimulation while producing effects that mirror those of lesions damaging the tissue stimulated (Perlmutter and Mink, 2006; Kringelbach et al., 2007). Here, we found that the effects of brief, high-frequency stimulation in the rostral ILn vary with the level of current applied and the timing of when it is applied. Higher levels of current produced deficits that resembled effects of lesions or reversible inactivation of the rostral ILn (Porter et al., 2001; Bailey and Mair, 2005) (Fig. 3), whereas lower levels had opposite effects, enhancing performance. Stimulation during delay and choice phases of DMTP affected performance, whereas stimulation during earlier initiation or sample phases did not.

The rostral ILn have been proposed as a site for treating acquired cognitive disorders with DBS (Schiff and Purpura, 2002; Schiff and Fins, 2007). Apart from one clinical case, there is little evidence for the benefits of this treatment in brain-injured individuals (Schiff et al., 2007). The usefulness of this approach is supported by evidence that high-frequency electrical stimulation of the rostral ILn can enhance memory-guided responding in intact rats. Previous work showed benefits of prolonged (30 min) stimulation on object recognition memory assessed by unreinforced exploratory activity (Shirvalkar et al., 2006). We observed beneficial effects of brief ( $1 \mathrm{~s})$ stimulation at low current levels (0.003-0.01 mA) on DMTP, a task known to depend on the rostral ILn as well as areas of cortex and basal ganglia that they innervate (Bailey and Mair, 2005). DMTP was similarly improved by the more prolonged effects of FG-7142 and orexin A microinjected in the area of the rostral ILn. Here, we observed comparable effects of these drugs in rats with or without $\mathrm{mPF}$ lesions, although the behavioral effects of these lesions were limited. Thus, to at least a limited extent, prefrontal pathology does not appear to interfere with beneficial effects of rostral ILn stimulation (Figs. 3, 4). Our results suggest that optimal levels of event-related stimulation in the rostral ILn may be an effective means to enhance cognitive functions, like working memory, that are disrupted by diseases involving frontal cortex or basal ganglia. Our findings also demonstrate the usefulness of eventrelated stimulation as a means to elucidate temporal relationships between neural activity and behavioral function.

\section{References}

Arnsten AF (2007) Catecholamine and second messenger influences on prefrontal cortical networks of "representational knowledge": a rational bridge between genetics and the symptoms of mental illness. Cereb Cortex 17 [Suppl 1]:i6-i15.

Bailey KR, Mair RG (2004) Dissociable effects of frontal cortical lesions on measures of visuospatial attention and spatial working memory in the rat. Cereb Cortex 14:974-985.

Bailey KR, Mair RG (2005) Lesions of specific and nonspecific thalamic nuclei affect prefrontal cortical-dependent aspects of spatial working memory. Behav Neurosci 119:410-419.

Bayer L, Eggermann E, Saint-Mleux B, Machard D, Jones BE, Mühlethaler M, Serafin M (2002) Selective action of orexin (hypocretin) on nonspecific thalamocortical projection neurons. J Neurosci 22:7835-7839.

Berendse HW, Groenewegen HJ (1991) Restricted cortical termination fields of the midline and intralaminar thalamic nuclei in the rat. Neuroscience 42:73-102.

Burianova H, Grady CL (2007) Common and unique neural activations in autobiographical, episodic, and semantic retrieval. J Cogn Neurosci 19:1520-1534.

Burk JA, Mair RG (1998) Thalamic amnesia reconsidered: excitotoxic lesions of the intralaminar nuclei, but not the mediodorsal nucleus disrupt place DMTS performance in the rat (Rattus norvegicus). Behav Neurosci 112:54-67.

Burk JA, Mair RG (2001) Effects of dorsal and ventral striatal lesions on delayed matching trained with retractable levers. Behav Brain Res 122:67-78.

Curró Dossi R, Paré D, Steriade M (1991) Short-lasting nicotinic and longlasting muscarinic depolarizing responses of thalamocortical neurons to stimulation of mesopontine cholinergic nuclei. J Neurophysiol 65:393-406.

Kinomura S, Larsson J, Gulyás B, Roland PE (1997) Activation by attention of the human reticular formation and thalamic intralaminar nuclei. Science 271:512-515.

Kringelbach ML, Jenkinson N, Owen SL, Aziz TZ (2007) Translational principles of deep brain stimulation. Nat Rev Neurosci 8:623-635.

Laureys S, Faymonville ME, Luxen A, Lamy M, Franck G, Maquet P (2000) Restoration of thalamocortical connectivity after recovery from persistent vegetative state. Lancet 355:1790-1791.

Mair RG (1994) On the role of thalamic pathology in diencephalic amnesia. Rev Neurosci 5:105-140.

Mair RG, Burk JA, Porter MC (1998) In the rat (Rattus norvegicus) lesions of frontal cortex, hippocampus, and the intralaminar thalamic nuclei have distinct effects on remembering. Behav Neurosci 112:772-792.

Manoach DS, Greve DN, Lindgren KA, Dale AM (2003) Identifying regional activity associated with temporally separated components of working memory using event-related functional MRI. Neuroimage 20:1670-1684.

Matsumoto N, Minamimoto T, Graybiel AM, Kimura M (2001) Neurons in the thalamic CM-Pf complex supply striatal neurons with information about behaviorally significant sensory events. J Neurophysiol 85:960-976.

McCormick DA, Huguenard JR, Bal T, Pape HC (1997) Electrophysiologi$\mathrm{cal}$ and pharmacological properties of thalamic GABAergic neurons. In: Thalamus, Vol 2 (Steriade M, Jones EG, McCormick DA, eds). Amsterdam: Elsevier.

Minamimoto T, Kimura M (2002) Participation of the thalamic CM-Pf complex in attentiona orienting. J Neurophysio 87:3090-3101.

Newman LA, Mair RG (2007) Cholinergic modulation of visuospatial responding in central thalamus. Eur J Neurosci 26:3543-3552.

Paus T (2000) Functional anatomy of arousal and attention systems in the human brain. Prog Brain Res 126:65-77.

Paxinos G, Watson C (1998) The rat brain in stereotaxic coordinates, Ed 4. San Diego: Academic.

Perlmutter JS, Mink JW (2006) Deep brain stimulation. Annu Rev Neurosci 29:229-257.

Peyron C, Tighe DK, van den Pol AN, de Lecea L, Heller HC, Sutcliffe JG, Kilduff TS (1998) Neurons containing hypocretin (orexin) project to multiple neuronal systems. J Neurosci 18:9996-10015. 
Porter MC, Koch J, Mair RG (2001) Effects of reversible inactivation of thalamo-striatal circuitry on delayed matching trained with retractable levers. Behav Brain Res 119:61-69.

Schiff ND (2008) Central thalamic contributions to arousal regulation and neurological disorders of consciousness. Ann N Y Acad Sci 1129:105-118.

Schiff ND, Fins JJ (2007) Deep brain stimulation and cognition: moving from animal to patient. Curr Opin Neurol 20:638-642.

Schiff ND, Purpura KP (2002) Towards a neurophysiological foundation for cognitive neuromodulation through deep brain stimulation. Thalamus Relat Syst 2:55-69.

Schiff ND, Giacino JT, Kalmar K, Victor JD, Baker K, Gerber M, Fritz B, Eisenberg B, Biondi T, O’Connor J, Kobylarz EJ, Farris S, Machado A, McCagg C, Plum F, Fins JJ, Rezai AR (2007) Behavioral improvements with thalamic stimulation after severe traumatic brain injury. Nature 448:600-603.

Shirvalkar P, Seth M, Schiff ND, Herrera DG (2006) Cognitive enhancement with central thalamic electrical stimulation. Proc Natl Acad Sci U S A 103:17007-17012.

Tanaka M (2007) Cognitive signals in the primate motor thalamus predict saccade timing. J Neurosci 27:12109-12118.
Tanibuchi I, Goldman-Rakic PS (2005) Comparison of oculomotor neuronal activity in paralaminar and mediodorsal thalamus in rhesus monkey. J Neurophysiol 93:614-619.

Van der Werf YD, Witter MP, Uylings HB, Jolles J (2000) Neuropsychology of infarctions in the thalamus: a review. Neuropsychologia 38:613-627.

Van der Werf YD, Witter MP, Groenewegen HJ (2002) The intralaminar and midline nuclei of the thalamus. Anatomical and functional evidence for participation in processes of arousal and awareness. Brain Res Rev 39:107-140.

Watanabe Y, Funahashi S (2004) Neuronal activity throughout the primate mediodorsal nucleus of the thalamus during oculomotor delayedresponses. II. Activity encoding visual versus motor signal. J Neurophysiol 92:1756-1769.

Wyder MT, Massoglia DP, Stanford TR (2004) Contextual modulation of central thalamic delay-period activity: representation of visual and saccadic goals. J Neurophysiol 91:2628-2648.

Zhang Y, Bailey KR, Toupin MM, Mair RG (2005) Involvement of ventral pallidum in prefrontal cortical-dependent aspects of spatial working memory. Behav Neurosci 119:399-409. 